\title{
Redundancy of conventional articular response variables used in juvenile chronic arthritis clinical trials
}

\author{
Nicolino Ruperto, Edward H Giannini
}

\begin{abstract}
Objective-To estimate the degree of redundancy among articular response variables used routinely in juvenile chronic arthritis (JCA) clinical trials.

Methods-We obtained data from a large, computerised databank holding information from multiple clinical trials in children with JCA to determine Pearson correlation coefficients for changes from baseline values in articular response variables. All 508 JCA patients who entered the analysis of efficacy of the original trials were included in the present study. An $r$ value of 0.7 or greater was considered
\end{abstract} evidence of colinearity.

Results-When changes in joint counts of articular manifestations were compared with changes in the respective severity scores (for example swollen joint count versus swelling severity score), the $r$ values were always $\geqslant 0 \cdot 7$. Three articular response variables related to the assessment of pain are all highly correlated with each other. The number of joints with active arthritis was correlated with the number of joints with swelling and the swelling score. Change in the overall severity score was highly correlated $(r \geqslant 0 \cdot 7)$ with change in nearly all articular response variables.

Conclusions-Many endpoints reported in JCA trials are redundant, especially counts and scores of the same articular measure. Eliminating redundant variables would provide the same information with less complexity, and decrease the probability of statistical error and ambiguous results.

Università di Pavia, IRCCS Policlinico

'S Matteo', Pavia, Italy N Ruperto

Williams S Rowe

Division of

Rheumatology, Children's Hospital

Medical Center,

Department of

Pediatrics,

University of

Cincinnati College

of Medicine,

Cincinnati,

Ohio, USA

E H Giannini

Correspondence to: Dr Edward H Giannini, Children's Hospital Medical Center, 3333 Burnet Avenue, Pav 2-129, Cincinnati, OH 45229-3039, USA.

Accepted for publication 13 September 1995 duplicative, being only minor variations of other measures, and ideally some could be eliminated without a subsequent loss of information. ${ }^{1-3}$ Furthermore, because statistical significance may arise by chance when multiple statistical tests are performed, the use of many articular response variables increases the likelihood of statistical error and of ambiguous results. ${ }^{4}$

In this study, we present a statistical assessment of the duplicative nature of some classical articular response variables used in JCA clinical trials. We obtained data from a computerised databank that contains all data from four randomised controlled trials of slower acting antirheumatic drugs in children with JCA $(n=551)$ conducted by the Pediatric Rheumatology Collaborative Study Group (PRCSG). Our hypothesis was that many variables are highly correlated, and some could be eliminated without loss of information.

\section{Patients and methods}

PATIENTS

In the original trials, eligible patients were enrolled and articular response variables assessed according to published, standardised methods of the PRCSG for the conduct of studies of antirheumatic medications in children with JCA. ${ }^{56}$ In brief, the first trial, published in 1986, was a 12 month study of D-penicillamine and hydroxychloroquine versus placebo involving 162 patients; $^{7}$ the second, published in 1990, was a six month study of oral gold (auranofin) versus placebo in 231 patients; ${ }^{8}$ the third, published in 1992, was a six month study of low doses and very low doses of methotrexate versus placebo in 127 patients $;{ }^{9}$ the fourth, published in 1994, was a six month study of intravenous immunoglobulin (IVIg) versus placebo in 31 patients with systemic illness. ${ }^{10}$ The present analysis includes only those patients who entered the efficacy subset of the trial in which they were enrolled. To be considered for efficacy the patient was required to: meet the eligibility criteria for the trial in which they were enrolled; receive active drug for a period long enough to enable them to experience an 'adequate biologic trial'; have taken at least $80 \%$ of the prescribed study medication; and have avoided major protocol violations related to concurrent medications.

Among the 551 patients of the core data bank of the PRCSG, 508 qualified for the efficacy analysis: 309 received the pharmacologically active agent and 199 received placebo.
Eleven clinical articular response variables were assessed in a total of 71 joints: 1) the number of swollen joints and 2) the swelling score (graded as $0=$ none; $1+=$ mild-definite swelling but with no blurring of normal skeletal outlines; $2+=$ moderate-definite obscuring of skeletal landmarks; $3+=$ severe - no discernible 
skeletal landmarks); 3) the number of joints with pain on motion or 4) tenderness, and 5 ) the pain on motion or 6) tenderness score (each graded as $0=$ none; $1+=$ mild - patient complains on joint movement or palpation; $2+=$ moderate - patient withdraws or changes facial expression on movement or palpation; $3+=$ severe-patient responds markedly to movement or palpation); 7) the number of joints with limited range of motion and 8 ) the limited range of motion score $(0=$ full range; $1+=1-25 \%$ limitation; $2+=26-50 \%$ limitation; $3+=51-75 \%$ limitation; $4+=76-100 \%$ limitation). In addition to these indices, the following variables were calculated and recorded: 9) the total number of joints with active arthritis (defined as swelling or, if no swelling is present, limitation of movement with either pain upon movement or tenderness); 10) the overall severity score (sum of all the severity ratings); and 11) the average duration of morning stiffness. For each articular response variable, the absolute change from the value observed at baseline (initial visit) to the value observed at the final visit (whether or not the patient completed the trial) was calculated.

\section{STATISTICS}

We determined Pearson correlation coefficients ( $r$ value) between absolute changes in the articular response variables from baseline values to the last visit. Evidence of colinearity was considered to be present if the $r$ value was $\geqslant 0 \cdot 7$. Regression analysis was carried out using the Pearson correlation option of the True Epistat package software, Version 4.01 (Epistat Sigma Services, Richardson, TX) and verified using the Pearson function for Excel, Version 5.0 (Microsoft Corporation).

\section{Results}

Among the 508 patients who qualified for the efficacy analysis in the original trials, 52 received D-penicillamine, 55 received hydroxychloroquine and 47 placebo; 113 received oral gold and 98 placebo; 75 received methotrexate $\left(10 \mathrm{mg} / \mathrm{m}^{2}\right.$ body surface area/week $(\mathrm{n}=38)$ or $5 \mathrm{mg} / \mathrm{m}^{2}$ body surface area/week $\left.(\mathrm{n}=37)\right)$ and 39 placebo; 14 received IVIg and 15 placebo.

Baseline and final visit values of all variables were available for all patients, with the exception of duration of morning stiffness, for which there were 39 missing values.
The table presents the $r$ values for all correlations related to the 508 patients who qualified for the efficacy analysis. When changes in joint counts were compared with changes in their respective scores, $r$ values were always $\geqslant 0 \cdot 7$. The four articular response variables related to the assessment of pain (pain on motion or tenderness and their respective severity scores) were all highly correlated with each other, with the exception of the tenderness score and the number of joints with pain on motion. The number of active joints was correlated with the number of swollen joints, the swelling score, and the overall severity score. Change in overall severity score was highly correlated with change in all articular response variables except the number of joints with limited range of motion and duration of morning stiffness. The latter did not show evidence of colinearity with any other articular response variable.

Similar results were obtained when analysis was performed separately for the 309 patients who received the active agent and for the 199 who received placebo (data not shown).

\section{Discussion}

Our data suggest that colinearity is frequently encountered among changes in those articular response variables typically reported in JCA clinical trials. Change in overall severity score was highly correlated with all but two of the variables (number of joints with limited range of motion and duration of morning stiffness), suggesting that this single index could be used instead of each of its components.

We have found few published data concerning the redundancy of articular response variables: those studies that do exist relate to adult rheumatoid arthritis. Anderson et al ${ }^{1}$ found a high correlation between the joint tenderness count and the joint swelling count and their respective scores. Similar results were obtained by Felson et $a l^{411}$ who found evidence of duplication between joint counts and their corresponding scores and between the tender joint count and swollen joint count.

In conclusion, the results of this study demonstrate that among the traditional articular response variables commonly used in JCA clinical trials there is a large degree of redundancy, especially between the count and score of the same articular measure. A smaller number of measures would yield the same clinical information with less complexity and a

Articular response variables for treated and placebo group patients $(n=508)$

\begin{tabular}{|c|c|c|c|c|c|c|c|c|c|c|}
\hline & $\begin{array}{l}\text { Swollen } \\
\text { joints } \\
\text { (No) }\end{array}$ & $\begin{array}{l}\text { Swelling } \\
\text { score }\end{array}$ & $\begin{array}{l}\text { foints with } \\
\text { POM } \\
\text { (No) }\end{array}$ & $\begin{array}{l}\text { POM } \\
\text { score }\end{array}$ & $\begin{array}{l}\text { Tender } \\
\text { joints } \\
\text { (No) }\end{array}$ & $\begin{array}{l}\text { Tender } \\
\text { score }\end{array}$ & $\begin{array}{l}\text { foints with } \\
\text { LROM } \\
\text { (No) }\end{array}$ & $\begin{array}{l}\text { LROM } \\
\text { score }\end{array}$ & $\begin{array}{l}\text { Active } \\
\text { joints } \\
\text { (No) }\end{array}$ & $\begin{array}{l}\text { Overall } \\
\text { severity } \\
\text { score }\end{array}$ \\
\hline $\begin{array}{l}\text { Swelling score } \\
\text { Joints with POM (No) } \\
\text { POM score } \\
\text { Tender joints (No) } \\
\text { Tender score } \\
\text { Joints with LROM (No) } \\
\text { LROM score } \\
\text { Active joints (No) } \\
\text { Overall severity score } \\
\text { DMS }\end{array}$ & $\begin{array}{l}0.90 \\
0.59 \\
0.56 \\
0.55 \\
0.53 \\
0.60 \\
0.55 \\
0.92 \\
0.74 \\
0.18\end{array}$ & $\begin{array}{l}0.62 \\
0.64 \\
0.55 \\
0.59 \\
0.56 \\
0.60 \\
0.83 \\
0.83 \\
0.19\end{array}$ & $\begin{array}{l}\frac{0.92}{0.71} \\
0.68 \\
0.49 \\
0.51 \\
0.66 \\
0.81 \\
0.17\end{array}$ & $\begin{array}{l}\frac{\mathbf{0 . 7 0}}{\mathbf{0 . 7 6}} \\
\mathbf{0 . 4 6} \\
0.57 \\
0.61 \\
\frac{0.87}{0.19}\end{array}$ & $\begin{array}{l}0.91 \\
0.42 \\
0.43 \\
0.59 \\
0.77 \\
0.17\end{array}$ & $\begin{array}{l}0.39 \\
0.47 \\
0.56 \\
0.83 \\
0.17\end{array}$ & $\begin{array}{l}0.79 \\
0.65 \\
0.65 \\
0.11\end{array}$ & $\begin{array}{l}0.59 \\
0.76 \\
0.12\end{array}$ & $\frac{0.76}{0.17}$ & 0.19 \\
\hline
\end{tabular}

An $r$ value $\geqslant 0.7$ (bold and underlined) was considered to indicate colinearity. POM $=$ Pain of passive motion; LROM $=$ limited range of motion; DMS = duration of morning stiffness. 
decrease in the probability of statistical error and ambiguous results. An international project is in progress to establish a core set of reliable, valid, non-redundant outcome variables for use in JCA clinical trials. A preliminary report of the progress of this project suggested that the following six response variables should be included in the core set of outcome measures: ${ }^{12}$ 1) physician global assessment of disease activity, 2) parent/patient global assessment of disease activity, 3) functional disability index, 4) number of joints with active arthritis, 5) number of joints with limited range of motion, and 6) erythrocyte sedimentation rate.

This work was supported in part by the Children's Hospital Research Foundation of Cincinnati, the Schmidlapp Foundation, the National Institutes of Health (AR42632), a Clinical Science Grant from the Arthritis Foundation and by the IRCCS Policlinico 'S Matteo', Pavia, Italy. We thank Professor Alberto Martini for his review of the manuscript.

1 Anderson J J, Felson D T, Meenan R F, Williams H J Which traditional measures should be used in theumatoid arthritis clinical trials? Arthritis Rheum 1989; 32: 1093-9.

2 Tugwell $P$, Boers $M$. OMERACT conference on outcome measures in rheumatoid arthritis clinical trials: measures in theumatoid arthritis clin

3 van der Heijde D M F M, Van 't Hof $M$, van Riel P L C M, Van de Putte L B A. Validity of single variables and indices to measure disease activity in rheumatoid arthritis. I Rheumatol 1993; 20: 538-41.
4 Felson D T. Choosing a core set of disease activity measures for rheumatoid arthritis clinical trials. F Rheumatol 1993; 20: $531-4$.

5 Brewer E J, Giannini E H Standard methodology for segment I, II, and III pediatric rheumatology for segment I, II, and In pediatric rheumatology 1982; 9: 109-13.

6 Giannini E H, Brewer E J. Standard methodology for segment I, II, and III pediatric rheumatology collaborative study group studies. II. Analysis and presentation of data. $\mathscr{f}$ Rheumatol 1982; 9: 114-22.

7 Brewer E J, Giannini E H, Kuzmina N, Alekseev L Penicillamine and hydroxychloroquine in the treatment of severe juvenile rheumatoid arthritis: Results of the USA-USSR double-blind, placebo controlled trial. $N$ Engl F Med 1986; 314: 1269-76.

8 Giannini E H, Brewer E J, Kuzmina N, Shaikov A, Wallin B, for the Pediatric Rheumatology Collaborative Study Group. Auranofin in the treatment of juvenile theumatoid arthritis. Results of the USA-USSR doubleblind, placebo controlled cooperative trial. Arthritis blind, placebo controlled

9 Giannini E H, Brewer E J, Kuzmina N, et al, for the Pediatric Rheumatology Collaborative Study Group. Methotrexate in resistant juvenile rheumatoid arthritis. Results of the USA-USSR double-blind, placebocontrolled trial. N Engl f Med 1992; 326: 1043-9.

10 Silverman E D, Cawkwell G D, Lovell D J, et al, for the Pediatric Rheumatology Collaborative Study Group. Intravenous immune globulin in the treatment of systemic juvenile rheumatoid arthritis: A randomized placebocontrolled trial. $₹$ Rheumatol $1994 ; 21$ : 2353-8.

11 Felson D T, Anderson J J, Boers M, et al. The American College of Rheumatology preliminary core set of disease activity measures for rheumatoid arthritis clinical trials. Arthritis Rheum 1993; 36: 729-40.

12 Giannini E H, Lovell D J, Felson D T, Goldsmith C H. Preliminary core set of outcome variables for use in JRA Preliminary core set of outcome variables for use in JRA
clinical trials [Abstract]. Arthritis Rheum 1994; 37 (suppl): S428. 